\title{
First step to build on index to detect microbial volatile organic compounds emitted by moulds growing on building materials.
}

\author{
Claudia FALZONE, Karla DINNE*, Martyna KUSKE**, Anne-Claude ROMAIN \\ University of Liege, Arlon Campus Environnement, Avenue de Longwy 185, 6700 Arlon, Belgium ; \\ * Belgian Building Institute, Avenue Pierre Holoffe 21, 1342 Limelette, Belgium, \\ ** Sami-Lux, Rue de la Station 49, 6900 Marloie, Belgium,
}

\begin{abstract}
Nowadays, the detection of moulds hidden in buildings is only possible after degradation of the building materials. In the early 2000s, a new approach is suggested to detect fungal contamination of building materials. This one is based on the determination of the VOC emitted by the moulds, called Microbial-VOC (MVOC). This study was conducted to screen the emission of MVOCs by three different moulds growing on specific materials (shower mat, plasterboard, wood wool). The carbon dioxide, as indicator of biological activity, was also measured. In this paper, the development of an integrated index was considered for a new approach in the detection of hidden moulds. The index will be an algorithm with various variables specific to the moulds (for example: $\mathrm{RH}, \mathrm{CO}_{2}$, single VOC and specific VOC pattern...). The goal is to propose an innovative and simple tool working with low cost sensors.
\end{abstract}

Index Terms - - MVOC; sensor; chemical analysis; indoor air

\section{INTRODUCTION}

The expansion of energy efficient buildings without consideration of the indoor air quality has serious impacts on the occupant's health. Among various agents that deteriorated indoor air quality, dampness is one of the most significant. In optimal conditions such as high level of humidity, the moulds are able to grow easily on building materials and can propagate rapidly in the whole structure. It is well-known that moulds are hazardous for the occupants if they are in contact with the spores, mycotoxins and the volatile organic metabolites emitted in the air [1].

Nowadays, there are different approaches to detect the presence of moulds in interiors. Visual inspection is seldom efficient for small growth and hidden sources. The usual way is to quantify and identify moulds after sampling and culture. New techniques appear but they still require laboratory analyses, are time consuming and expensive. At the end of the 1990s and in the early 2000's, an approach based on analysis of MVOCs (Microbial Volatiles Organics Compounds) have been studied [2-7].
In fact, in the literature, several MVOCs are usually selected to be linked to moulds growth: 2-methyl-1-propanol, 3methyl-1-butanol, 3-methyl-2-butanol, 2-pentanol, 3octanol, 1-octen-3-ol, 2-octen-1-ol, 3-Methylfuran, 2hexanone, 2-heptanone, 3-octanone, 2-methylisoborneol, 2isopropyl-3-methoxy-pyrazine, geosmine and dimethyl disulphide [6]. It is also demonstrated that VOCs mixture is different at each stage of growth [7]. In addition to $\mathrm{VOC}, \mathrm{CO}_{2}$ is also induced by the metabolic activity [6]. The inherent building material emissions seem to be altered by the presence of moulds on the material. This variation can be caused by VOC transformation or deterioration and consumption of the material's VOCs by the moulds [6],

Even if several studies are carried out on MVOC, there are still no handheld devices on the market able to detect hidden moulds in dwellings with non-invasive tests, in particular by VOC measurement.

There are several difficulties in using VOC measurement to detect moulds that can explain this fact. Among them, existing VOC background in indoor air and low concentration of MVOC usually lower than the VOC background are the major ones. Several studies showed that the VOC pattern is more typical of moulds than single compounds. Even if these moulds patterns were characterised, the composition of the indoor air would risk to cover them up. A previous study was already performed with MOS sensor [8]. The $\mathrm{CO}_{2}$ sensor was not used at that time. To improve the approach, using additional parameters as for instance $\mathrm{CO}_{2}$ concentration, humidity level, the type of building materials to build up an integrative index to give the probability value of the presence/absence of moulds could be a better approach. The aim of this student work is to highlight first if this index makes sense. The idea behind is developing a non-invasive device with a multi-sensor array dedicated for moulds detection.

\section{MATERIALS AND METHODS}

Three typical moulds of indoor air were selected: Alternaria alternata (IHEM 19366, plantain (Arkansas), environment strain come from the BCCM), Aspergillus versicolor (IHEM 05058, cellophane (Indiana), strain come from the BCCM) 


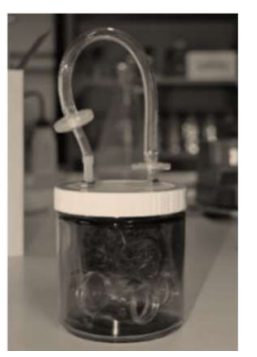

\begin{tabular}{|l|c|c|c|c|}
\hline \multicolumn{4}{|c|}{ Table 1: presentation of the samples. } \\
\hline & $\begin{array}{c}\text { Cla. } \\
\text { Inv. }\end{array}$ & $\begin{array}{c}\text { Alt. } \\
\text { alt. }\end{array}$ & $\begin{array}{c}\text { Asp. } \\
\text { ver. }\end{array}$ & Blanks \\
\hline Wood wool & - & - & - & $\begin{array}{c}2 \text { wet } \\
1 \text { dry }\end{array}$ \\
\hline Plasterboard & 3 & 3 & 3 & $\begin{array}{c}1 \text { wet } \\
1 \text { dry }\end{array}$ \\
\hline Shower mat & 3 & 3 & 3 & $\begin{array}{c}1 \text { wet } \\
1 \text { dry }\end{array}$ \\
\hline Petri dishes & 1 & 1 & 1 & 1 wet \\
\hline
\end{tabular}

Photo 1 growth chamber with wood wool

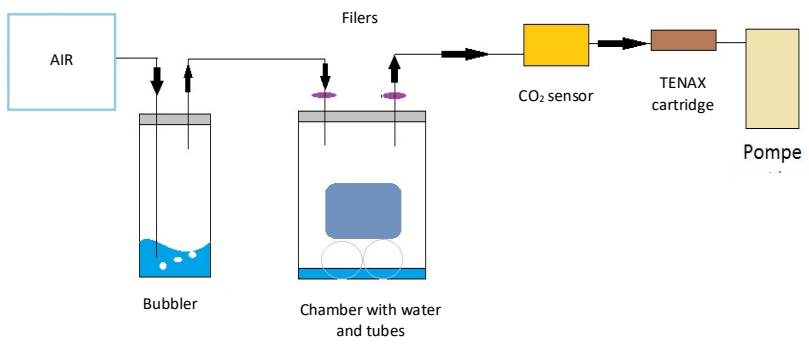

Figure 1 Illustration of the sampling method. left to right: humidified air, air was aspirated by a pump with a flow of $50 \mathrm{ml} / \mathrm{min})$, through a TENAX® TA cartridge, online $\mathrm{CO}_{2} \mathrm{IR}$ sensor

and Cladosporium inversicolor (IHEM 06555, carpet dust (Paris), strain come from the BCCM).

The experiments have been performed on 3 different building materials: plasterboard, shower mat and wood wool. Malt extract agar was used as reference substrate for the moulds. Plasterboard and shower mat were sterilised with UVC light during 15 minutes and the growth glass chambers were let 20 minutes in on oven at $125^{\circ} \mathrm{C}$. Wood wool was intentionally not sterilised.

Plasterboard and shower mat were inoculated with each of the 3 moulds (and a blank material sample -without inoculation). The wood wool was not contaminated, in order to see if there was a spontaneous fungal growth in wet conditions. Petri dishes were also contaminated with each mould and one was not contaminated. (table 1). After contamination, they were placed in the growth sterile chambers containing water in the bottom. The material was deposited above glass tubes in order to avoid water contact (photo 1). The chamber was let, during 21 days, inside a proofer at $24^{\circ} \mathrm{C}$ and near $100 \% \mathrm{RH}$. After 21 days of incubation, the VOCs were adsorbed on TENAX ${ }^{\circledR}$ TA. The sampling method is illustrated on the figure 1. Synthetic air was preferred to ambient air in order to exclude VOC present in the ambient air. The bubbler controlled the relative humidity of the samples. Particles filters $(0,2 \mu \mathrm{m})$ were used to avoid moulds contamination of the ambient air as well as contamination of the samples with external spores. The $\mathrm{CO}_{2}$ sensor was placed between the chamber and the cartridge. The air flow rate was $50 \mathrm{ml} / \mathrm{min}$ during 8 minutes. Therefore, the total chamber headspace was collected $(400 \mathrm{ml})$. The analysis of the MVOC sampled on

\begin{tabular}{|c|c|c|c|c|}
\hline \multicolumn{5}{|c|}{$\begin{array}{l}\text { Table 2: } \mathrm{CO}_{2} \text { concentration in ppm. The CO2 concentration in empty } \\
\text { chamber in wet condition was } 240 \text { ppmv. [minimal-maximal } \\
\text { concentration obtained on } 3 \text { samples for plasterboard, all samples for } \\
\text { shower mat and } 1 \text { sample for petri dishes] }\end{array}$} \\
\hline & Cla. Inv. & Alt. alt. & Asp. ver. & Blanks \\
\hline Wood wool & - & - & - & $\frac{\text { Wet }}{[920-2055]}$ \\
\hline Plasterboard & $\begin{array}{l}{[640-} \\
1945]\end{array}$ & [480-670] & $\begin{array}{l}{[460-} \\
1210]\end{array}$ & 1260 \\
\hline Shower mat & \multicolumn{3}{|c|}{ [240-300] } & 220 \\
\hline Petri dishes & 350 & 420 & 420 & 270 \\
\hline
\end{tabular}

the TENAX ${ }^{\circledR}$ TA cartridge were carried out with a TD-GCMS (TD: Markes International ${ }^{\circledR}$ Ultra 50/50 version1; GC: Thermo ${ }^{\circledR}$ Trace GC ultra; MS: Thermo ${ }^{\mathrm{TM}}$ DSQII). After thermal desorption, the compounds were eluted through a capillary column RESTEK Rxi ${ }^{\circledR}-5 \mathrm{~ms}$ (length $6 \mathrm{~m}$, internal diameter $0,25 \mathrm{~mm}$ ). This later has a stationary phase with low polarity (thickness $0,25 \mu \mathrm{m}$; Crossbond $\AA$ : $5 \%$ diphényle / 95\% diméthyle polysiloxane), a low bleeding and an operating temperature between $-60^{\circ} \mathrm{C}$ and $330 / 350^{\circ} \mathrm{C}$.

The temperature programing was $38^{\circ} \mathrm{C}$ during 5 minutes with a ramp of $5^{\circ} \mathrm{C} /$ minute and a final temperature of $180^{\circ} \mathrm{C}$, maintained during 1 minute. The total running time was 34,40 minutes. NIST mass spectrum database was used for the identification of the compounds.

\section{RESULTS}

\subsection{Visual inspections}

A mould development was visible on the 9 plasterboards samples after contamination. Systematically, a development of white coloured mould was also observed. This one was not inoculated. So even after UVC and oven sterilisation a natural development occurred. It was similar for the wood wool samples and for the blank plasterboard in wet conditions. The mould growth was more difficult on the shower mat.

\subsection{Measurement of carbon dioxide}

The $\mathrm{CO}_{2}$ concentrations are listed in table 2. The values for the petri dishes with moulds were higher than for the reference. A high $\mathrm{CO}_{2}$ level (above $400 \mathrm{ppmv}$ ) was measured for the wood wool samples in wet conditions, for the inoculated plasterboard samples as well as for the noninoculated plasterboard (contaminated by an external mould). Shower mat was the exception: there was no significant difference between $\mathrm{CO}_{2}$ in blank and inoculated samples. This observation confirmed the weak development of moulds on this material.

\subsection{VOC Identification}

VOC emissions were slightly different between building material in dry conditions and the same material in wet conditions. 
Chromatograms highlighted different VOC and various concentrations when there was fungal growth on the materials.

It was surprising to observe the disappearance of some VOCs emitted by the plasterboard samples when moulds were growing on them: 1-hexene, 1,3-pentadienne, 2,4-dimethyl1-heptene and hexane,3-methyl.

On the contrary, new VOCs could appear when there was fungal growth on the materials: 1- nonene (Alt. alt. and Asp. ver. on 2 substrates) and 2-propanone,1-methoxy (Cla. inv. on 2 substrates).

In the case of wood wool, new VOCs appeared and when the conditions changed from dry to wet some VOCs disappeared. Other specific VOCs were released only during the growth of one fungal species.

\section{DISCUSSION}

The $\mathrm{CO}_{2}$ concentrations were in correlation with the visuals inspections. More important was the moulds growth, higher was the $\mathrm{CO}_{2}$ concentration. The $\mathrm{CO}_{2}$ demonstrated the presence of metabolic activity and therefore the development of moulds. The results confirmed that the VOCs were function of moulds species and of substrates. The similar results are shown in other works [3;5]. Moreover, VOC mixtures were typical of the association with a mould species and a specific substrate (the building material) and, therefore specific VOC pattern could be used for identification.

The preliminary data suggest that it is conceivable to integrate chemical (MVOC, $\mathrm{CO}_{2}, \mathrm{O}_{2} \ldots$ ) and physical (temperature, humidity...) variables to build up a detection index. A multi-sensors device combined with this index would be non-invasive and easy to use for actors in the fields. Low cost sensors are favoured to reduce the manufacturing cost of the system.

\section{CONCLUSIONS}

The data showed that $\mathrm{CO}_{2}$ concentrations, as a result of moulds metabolic activities, were enough high ( $>600 \mathrm{ppmv})$ to be distinguished from the $\mathrm{CO}_{2}$ level in ambient air.

The diversity of moulds, substrates and environmental parameters increases the complexity for e-nose application and several studies are further required.

This preliminary study suggested an integrated approach to detect moulds in buildings. Alone, a MVOC footprint is not able to detect the presence of moulds with enough certainty. However, combination of VOC pattern with other variables that are characteristic of ideal development conditions (RH...) and of metabolic activities $\left(\mathrm{CO}_{2}\right)$ should increase the reliability of detection device.

In the long term, creation of index must be the solution for detected hidden moulds. This approach exists for thermal comfort determination [9]. This one integrates objective and subjective components. A similar study can be conducted for predictive index hidden moulds development.

\section{REFERENCES}

[1] B. Flannigan, R. A. Samson, and J. D. Miller, Microorganisms in Home and Indoor Work Environments: Diversity, Health Impacts, Investigation and Control, 2nd edition. Flannigan, Brian Samson, $\mathrm{R}$ A Miller, J. David, 2011.

[2] A.-L. Sunesson, C.-A. Nilsson, B. Andersson, and G. Blomquist, "Volatile métabolites produced by two fungal species cultivates on buildings materials," Ann. Occup. Hyg., vol. 40, no. 4, pp. 397-410, Aug. 1996.

[3] S. Moularat, E. Robine, O. Ramalho, and M. A. Oturan, "Detection of fungal development in a closed environment through the identification of specific VOC: demonstration of a specific VOC fingerprint for fungal development.," Sci. Total Environ., vol. 407, no. 1, pp. 139-46, Dec. 2008.

[4] M. Kuske, R. Rubio, A-C. Romain, J. Nicolas, and S. Marco, "Fuzzy k-NN applied to moulds detection," Sensors Actuators, B Chem., vol. 106, pp. 52-60, 2005.

[5] M. Kuske, M. Padilla, A-C. Romain, J. Nicolas, R. Rubio, and $\mathrm{S}$. Marco, "Detection of diverse mould species growing on building materials by gas sensor arrays and pattern recognition," Sensors Actuators, B Chem., vol. 119, pp. 33-40, 2006.

[6] A. Korpi, J. Järnberg, and A-L. Pasanen, "Microbial volatile organic compounds," Critical reviews in toxicology, vol. 39, pp. 139-193, 2009.

[7] M. Lor, K. Vause, K Dinne, E. Goelen, F. Maes, A-C Romain, J. Nicolas, and C. Degrave, "Horizontal evaluation method for the implementation of the construction products directive - emissions from construction products into indoor air," 9th International Conference and Exhibition on Healthy Buildings, vol. 1, pp 356360,2009 .

[8] Kuske, M., Padilla, M., Romain, A C., Nicolas, J., Rubio, R., Marco, S., 2004. "Detection of Moulds Growing on Building Materials by Gas Sensor Arrays and Pattern Recognition," Data Process 452-456.

[9] ISO 7730, "Ergonomics of the thermal environment -- Analytical determination and interpretation of thermal comfort using calculation of the PMV and PPD indices and local thermal comfort criteria", 2005. 